\title{
Toxicity evaluation of pH dependent stable Achyranthes aspera herbal gold nanoparticles
}

\author{
Alok Tripathi $\cdot$ Sarika Kumari $\cdot$ Arvind Kumar
}

Received: 19 December 2014/ Accepted: 4 February 2015/Published online: 17 February 2015

(C) The Author(s) 2015. This article is published with open access at Springerlink.com

\begin{abstract}
Nanoparticles have gained substantial attention for the control of various diseases. However, any adverse effect of herbal gold nanoparticles (HGNPs) on animals including human being has not been investigated in details. The objectives of current study are to assess the cytotoxicity of HGNPs synthesized by using leaf extract of Achyranthes aspera, and long epoch stability. The protocol deals with stability of HGNPs in $\mathrm{pH}$ dependent manner. Visually, HGNPs formation is characterized by colour change of extract from dark brown to dark purple after adding gold chloride solution $(1 \mathrm{mM})$. The $100 \mu \mathrm{g} / \mathrm{ml}$ HGNPs concentration has been found nontoxic to the cultured spleenocyte cells. Spectrophotometric analysis of nanoparticles solution gave a peak at $540 \mathrm{~nm}$ which corresponds to surface plasmon resonance absorption band. As per scanning electron microscopy and Transmission electron microscopy (TEM), size of HGNPs are in the range of 50-80 nm (average size $70 \mathrm{~nm}$ ) with spherical morphology. TEM-selected area electron diffraction observation showed hexagonal texture. HGNPs showed substantial stability at higher temperature $\left(85^{\circ} \mathrm{C}\right), \mathrm{pH} 10$ and salt concentration $(5 \mathrm{M})$. The zeta potential value of HGNPs is $-35.9 \mathrm{mV}$ at temperature $25^{\circ} \mathrm{C}, \mathrm{pH} 10$ showing its good quality with better stability in comparison to $\mathrm{pH} 6$ and $\mathrm{pH}$ 7. The findings advocate that the protocol for the synthesis of HGNPs is easy and quick with good quality and long epoch stability at $\mathrm{pH} 10$. Moreover, non-toxic dose could be widely applicable for human health as a potential nanomedicine in the future to cure diseases.
\end{abstract}

A. Tripathi · S. Kumari · A. Kumar $(\bowtie)$

Faculty of Science, School of Biotechnology, Banaras Hindu

University, Varanasi 221005, UP, India

e-mail: k_arvindk@rediffmail.com; k_arvindk@yahoo.com
Keywords Cytotoxicity $\cdot$ Medicinal $\cdot$ Herbal $\cdot$ Gold nanoparticles $\cdot$ Zeta potential

\section{Introduction}

Nanotechnology has created excitement in the area of life sciences, biotechnology and biomedical sciences (Prabhu et al. 2010). It could be defined as the technology that administered knowledge of material at molecular and atomic level. Herbal nanoparticles render completely novel and superior properties in context to size, distribution and stability (Sharma et al. 2009). Most significant features and challenging task of nanotechnology and herbal nanoparticles are the synthesis of stable nanoparticles in a range between 10 and $100 \mathrm{~nm}$ sizes. The nanoparticles must show superior novel properties in respect to the existing properties showed by bulk materials. The improved properties should be revealed in size, texture and distribution patterns of nanoparticles (Willems 2005). Nanotechnology in combination with biotechnology has given a new area of research and application called as nano-medicine and nanobiotechnology. Nano-biotechnology is most recent and an emerging field that also deals with eco-friendly synthesis of nano-materials by using biological materials (Gilaki 2010) for an application in medical field to control various human diseases. Among different methods used for the synthesis of nanoparticles such as physical, chemical and biological; biological methods using plant extracts, enzymes and microorganisms is most promising and eco-friendly (Mohanpuria et al. 2008). Herbal medicinal plant extracts mediated synthesis of nanoparticles have various advantages over other biological methods such as microbial and enzymatic based processes since it does not require cell cultures and its maintenance and also easy to handle for

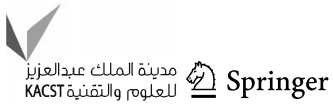


synthesis in large amounts for further use (Shankar et al. 2004a, b; Singh et al. 2013). Metallic nanoparticles synthesized using biological systems have given more preference due to its advantageous chemical, optical, electronic and photo electrochemical properties along with cost effectiveness without any side-effects (Chandrasekharan et al. 2000; Królikowska et al. 2003; Kumar et al. 2003; Peto et al. 2002). Metallic nanoparticles may be gold, silver, zinc, iron and platinum. Recently, herbal metallic nanoparticles have gained wide applications not only in medical, pharmaceutical and cosmetic products but also as a product that are of daily uses, for example toothpastes, detergents, soaps and shampoos, etc. Gold is a widely used metal since ancient times in different forms and as an ayurvedic revitalization medicine in India and China (Bhattacharya and Murkherjee 2008). In recent time, gold nanoparticles have been used for drug delivery and in diagnostic medicine (Bhumkar et al. 2007). Different types of herbal plants have been used for the synthesis of HGNPs. For examples Coriandrum sativum, Cinnamomum camphora and Tamarindus indica are well known plants that have been used for the synthesis of HGNPs (Ankamwar et al. 2005; Huang et al. 2007; Narayanan and Sakthivel 2008). Researchers and scientists have used medicinal plants such as Alfalfa, Azadirachta indica and Aloevera for the synthesis of both herbal gold and herbal silver nanoparticles (Shankar et al. 2004a; Chandran et al. 2006; Gardea-Torresdey et al. 2002, 2003). Nanoparticles with different properties, textures and formation rates can be acquired by using different parameters of temperature, $\mathrm{pH}$ and substrate concentration (Gericke and Pinches 2006).

Achyranthes aspera of amaranthaceae family is a weed, present on the roadside and waste places throughout India. This plant has been reported for many medicinal values. Its common name is Prickly Chaff Flower/Latzeera/Chirchita. Indian and Chinese medicinal manuscripts have documentation and therapeutic benefits of this plant parts such as root, shoot and seed. Medicinal significance of this plant is in the treatment of various diseases such as bronchial asthma, heart disease, piles, leprosy, whooping cough and dysentery (Singh 1995; Suresh et al. 1985; Tripathi et al. 1963).

In present research work we proposed a rapid ecofriendly method for aqueous synthesis of stable HGNPs by the bio-reduction of gold chloride $\left(\mathrm{HAuCl}_{4}\right)$ using the leaf extract of A. aspera, in $\mathrm{pH}$ dependent manner. This herbal plant has been used for synthesis of HGNPs because it contains bioactive compounds like chlorogenic acid, quercitin, chrysin, quinic acid, etc. that most probably worked as a reducing agent along with other unknown constituents (Narayan and Kumar 2013). Also, herbal extract of this plant has been experimentally proved for its anti-inflammatory and anti-cancerous properties (Narayan and Kumar 2014). HGNPs characterization is done by UV-Vis spectrum, scanning electron microscope (SEM) and transmission electron microscope (TEM) and selected area electron diffraction (SAED) while stability has been confirmed by measuring zeta potential. Cytotoxicity assay has been performed using spleenocyte cultured cells to evaluate any harmful effects of HGNPs, so particles could be applied as nano-medicine to mitigate diseases in future.

\section{Materials and methods}

Chemicals and collection of medicinal plants

Gold chloride $\left(\mathrm{HAuCl}_{4}\right)$ was procured from Sisco Research Laboratories Pvt. Ltd. (SRL), Mumbai, India. Dulbecco's modified Eagles medium (DMEM) was purchased from Genetix Biotech Asia Pvt. Ltd, India. 6-well culture plate was purchased from Nest Biotech Co. Ltd, China. Ammonium chloride $\left(\mathrm{NH}_{4} \mathrm{Cl}\right)$, sodium bicarbonate $\left(\mathrm{NaHCO}_{3}\right)$, ethylene diamine tetra acetate (EDTA), sodium chloride $(\mathrm{NaCl})$ and sodium hydroxide $(\mathrm{NaOH})$ were purchased from Merck, Mumbai, India. A. aspera herbal plant was collected from the roadside in BHU Campus. To avoid any metal contamination, glasswares were washed with chromic acid before using in the experiment.

\section{Preparation of herbal extract}

Whole plants of A. aspera collected and leaves were used for extract preparation. In brief, only fresh, good leaves were plucked from the plants and subjected to proper washing under running tap water. Leaves were then thoroughly washed with double distilled water (DDW) and cut into incise form for extract preparation. $40 \mathrm{~g}$ cut leaves of A. aspera were boiled with $100 \mathrm{ml}$ of DDW in Erlenmeyer flask on hot plate. After boiling, the solution is cooled to room temperature. The solution was filtered with filter paper either to use immediately or to store at $4{ }^{\circ} \mathrm{C}$ till further experimental use.

Synthesis of HGNPs using the leaf extract of A. aspera

Initially $1 \mathrm{mM}$ gold chloride solution was prepared in DDW. Filtered aqueous leaf extract and gold chloride solution was mixed in 1:9 ratios for the synthesis of HGNPs. Gold chloride solution in other tube was taken as a standard. Mixture of leaf extract and gold chloride solution was incubated at room temperature with continuous stirring for 15-30 min. Within 15 min colour of solution started changing into light pink, which is an indication of 
synthesized HGNPs. Solution was centrifuged at $12,000 \mathrm{rpm}$ for $30 \mathrm{~min}$ at $25^{\circ} \mathrm{C}$. Supernatant was discarded and pellet was washed with DDW. Centrifugation and washing step was repeated twice for better separation of any biological entities from HGNPs. Finally pellet was re-suspended in DDW. The dark colloidal purple colour HGNPs were stored for further experimental confirmation.

\section{Characterisation of HGNPs by UV-Vis spectral} analysis

UV-Vis spectroscopy technique is useful for detection, identification and characterization of metallic and herbal metallic nanoparticles. The nanoparticles and HGNPs have optical properties that are sensitive to shape, size, and refractive index. Absorption peak of HGNPs were recorded in the absorption range between 400 and $800 \mathrm{~nm}$ using quartz cuvette of $10 \mathrm{~mm}$ optical path length via double beam UV-Vis absorption spectrophotometer (JASCO V-630). DDW was used as blank.

Characterisation of HGNPs by scanning electron microscopic (SEM) analysis

SEM technique was used to know the surface topography and size of the nanoparticles present in the sample. Beam of electrons interacting with the atoms present on the surface of nanoparticles in sample develop the detectable signals. These detectable signals contain information about surface topography to provide 3D structure or image of the particles. Before analysis with SEM, synthesized nanoparticles were centrifuged and washed with DDW. The pellet was sonicated by ultrasonicator to remove any clumping of HGNPs. The sample is finally lyophilized. The lyophilized nanoparticles were mounted on the copper $(\mathrm{Cu})$ stubs and SEM is done with secondary electron detector by applying 20-40 kV voltage with Fei Quanta 200 for the development of micrograph.

\section{Characterisation of HGNPs by TEM- and TEM-SAED analysis}

TEM is used to explore the morphology of very small size particles present in the sample. Beam of electrons interacting with the prepared thin film of nanoparticles specimen, finally produces magnified image. Before application to TEM, sample was sonicated with ultrasonicator to remove the aggregation of HGNPs. Sample was mounted on carbon coated copper $(\mathrm{Cu})$ grid. The sample is dried on the grid and used for examination in a Fei Tecnai-20 $\mathrm{G}^{2}$ model TEM operated at $200 \mathrm{kV}$. The micrograph is developed for observation and analysis. For TEM-SAED, single particle is selected for the electron microscopy.
Measurement of zeta potential of synthesized HGNPs on different $\mathrm{pH}$

Zeta potential is a potential difference between the two suspended particles present in colloidal suspension. It is a physical property which deals with the stability of nanoparticles. Zeta potential values may be positive or negative and values above $30 \mathrm{mV}$ shows nanoparticles stability. $1 \mathrm{~N} \mathrm{NaOH}$ was used to adjust the desired $\mathrm{pH}$ of HGNPs solution. Sample was sonicated to avoid the agglomeration of HGNPs. Clear disposable zeta cell was used to calculate the zeta potential value of samples at different $\mathrm{pH}$ that is at $\mathrm{pH} 6, \mathrm{pH} 7$ and $\mathrm{pH} 10$ at fixed temperature $25{ }^{\circ} \mathrm{C}$. Zeta potential of HGNPs was determined by Zetasizer Nanoseries (Malvern Instruments Nano ZS) at different $\mathrm{pH}$ such as $\mathrm{pH} 6, \mathrm{pH} 7$ and $\mathrm{pH} 10$ at $25^{\circ} \mathrm{C}$.

Measurement of HGNPs stability under different temperature, salt concentration and $\mathrm{pH}$

Impact of temperature, salt concentration $(\mathrm{NaCl})$ and $\mathrm{pH}$ on the stability of synthesized HGNPs was optimised by measuring the absorbance using spectrophotometer. Spectra were recorded at different temperature that is at 55, 65, 75 and $85^{\circ} \mathrm{C}$, at different $\mathrm{NaCl}$ concentrations that is at 1 , 2, 3, 4 and 5 and at different $\mathrm{pH}$ that is at $\mathrm{pH} 6, \mathrm{pH} 7, \mathrm{pH} 9$ and $\mathrm{pH} 10$ using spectrophotometer.

Spleenocyte cells preparation and culture for cytotoxicity assay

Balb/c mice were sacrificed according to the guidelines of ethical committee of Banaras Hindu University, Varanasi, UP, India. Spleen were dissected out from mice, washed with cold phosphate buffered saline (PBS) and cell suspension was prepared by mincing tissues in incomplete Dulbecco's modified eagles medium (DMEM). RBCs lysis buffer $\left(1 \mathrm{mM} \mathrm{NaHCO}_{3}, 0.15 \mathrm{M} \mathrm{NH}_{4} \mathrm{Cl}, 0.1 \mathrm{mM}\right.$ EDTA at $\mathrm{pH}$ 7.4) was used for the lysis of RBCs. Spleenocytes were washed twice with incomplete DMEM medium and centrifuged at $2,000 \mathrm{rpm}$ for $10 \mathrm{~min}$ at $4{ }^{\circ} \mathrm{C}$. Pellet was resuspended in incomplete DMEM medium and trypan blue exclusion assay counting was done by using hemocytometer to know the viability of cells. Total $2 \times 10^{6}$ viable cells/ml were seeded in each well of 6-well culture plate and incubated in $\mathrm{CO}_{2}$ incubator for the proper growth up to $2 \mathrm{~h}$ at $37{ }^{\circ} \mathrm{C}$ and $5 \% \mathrm{CO}_{2}$.

Cytotoxicity assay and viability assay with HGNPs

Spleenocyte cells were treated with different concentration of synthesized HGNPs (20, 80, 100, 200 and $400 \mu \mathrm{g} / \mathrm{ml})$ and incubated in $\mathrm{CO}_{2}$ incubator at $37{ }^{\circ} \mathrm{C}$ with $5 \% \mathrm{CO}_{2}$ for 
$1 \mathrm{~h}$. After $1 \mathrm{~h}$ of incubation cells were collected by trypsinization and were pelleted by centrifugation $\left(2,000 \mathrm{rpm} / 4{ }^{\circ} \mathrm{C} / 10 \mathrm{~min}\right)$. Pellet was re-suspended in the incomplete DMEM medium and viable cells were counted by trypan blue exclusion assay using hemocytometer.

\section{Results and discussion}

In current study HGNPs were synthesized using leaf extract of medicinal plant $A$. aspera that has been reported for its anti-inflammatory and anti-cancerous properties. Fresh green leaves of this plant were used for synthesis of HGNPs. First evidence for the formation of HGNPs was obtained from the colour change of the leaf extract solution after mixing with $1 \mathrm{mM} \mathrm{HAuCl}_{4}$ solution. In the beginning, $1 \mathrm{mM} \mathrm{HAuCl}_{4}$ and leaf extract were, respectively, light yellow and dark brown in colour that formed dark colloidal purple colour (Fig. 1) after mixing together. This is a visual proof for the formation of HGNPs as reported earlier (Turkevich et al. 1951). The A. aspera has been reported to contain various bioactive components such as phenolic acids, flavonoids and many unknown compounds as proved by UPLC method (Narayan and Kumar 2013). Most probable reason for the formation of HGNPs is the bio-reduction of $\mathrm{HAuCl}_{4}$ solution by the various known and unknown components present in the leaf extract of $A$. aspera which is in concordance with the findings of Smitha et al. (2009). The green leaves were preferred over the other parts of the plant due to its high photosynthesis rate and availability of more $\mathrm{H}^{+}$ions in the extract to reduce $\mathrm{HAuCl}_{4}$ into HGNPs.

$\mathrm{UV}-\mathrm{Vis}$ spectral analysis

Spectroscopic evidence for the formation of HGNPs comes from the UV-Vis spectrum of the solution taken between the range $400-800 \mathrm{~nm}$. HGNPs solution shows a strong peak at nearly $540 \mathrm{~nm}$ (Fig. 2), which might be due to the surface plasmon resonance (SPR), known as quantum mechanical phenomenon of metallic nanoparticles. A single spectrum at $540 \mathrm{~nm}$ indicates the good quality of HGNPs. Moreover, according to Mie theory, formation of one SPR absorption band is an indication of the smallness of gold nanoparticles. Presence of two or more than two SPR bands is indication that the particles are anisotropic. Many scientific reports have indicated that aged nanoparticles due to agglomeration of particles could be reason for more than one peak (Henglein 1993). However, we could not get anisotropic phenomenon of HGNPs hence got only single peak at $540 \mathrm{~nm}$.

Scanning electron microscopy (SEM) and transmission electron microscopy (TEM) analysis

SEM and TEM techniques illustrate the morphology, shape and size of HGNPs. Image of HGNPs were recorded at 40,000 magnifications by the SEM. Nanoparticles image acquired by SEM clearly point out that the HGNPs are
Fig. 1 Herbal gold nanoparticles $(H G N P s)$ synthesis from leaf extract of $A$. aspera and visual identification a color of gold chloride $\left(\mathrm{HAuCl}_{4}\right)$ solution, b color of $\mathrm{A}$. aspera leaf extract, $\mathbf{c}$ color of HGNPs solution

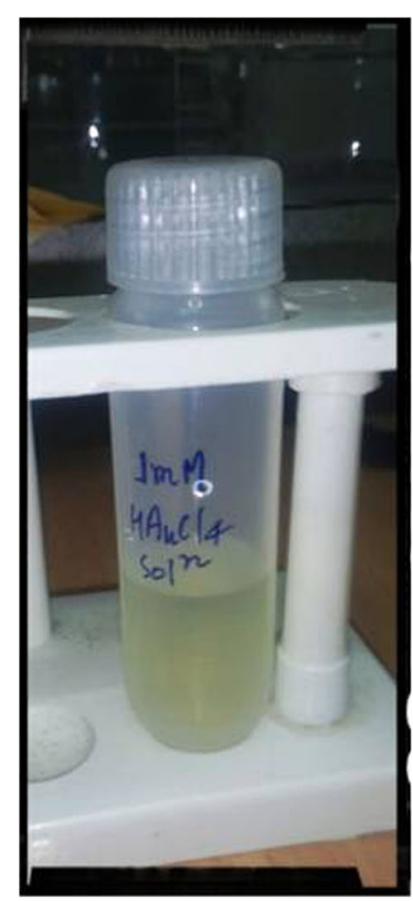

a $\mathrm{HAuCl}_{4}$ solution

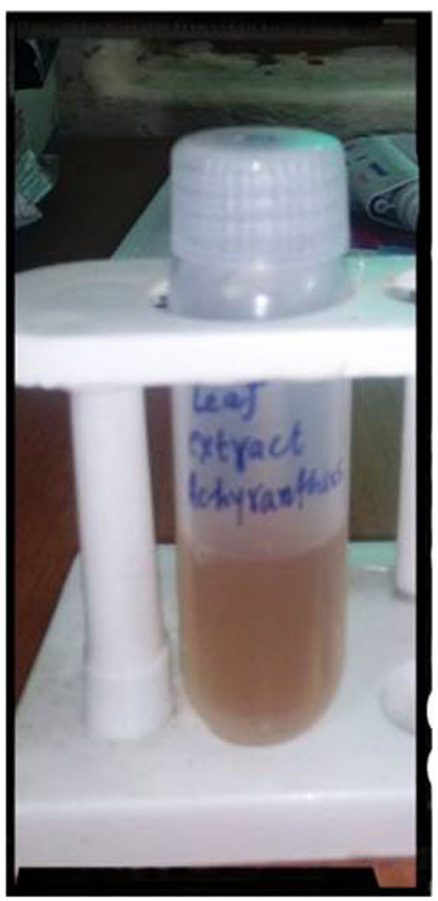

b A. aspera leaf extract

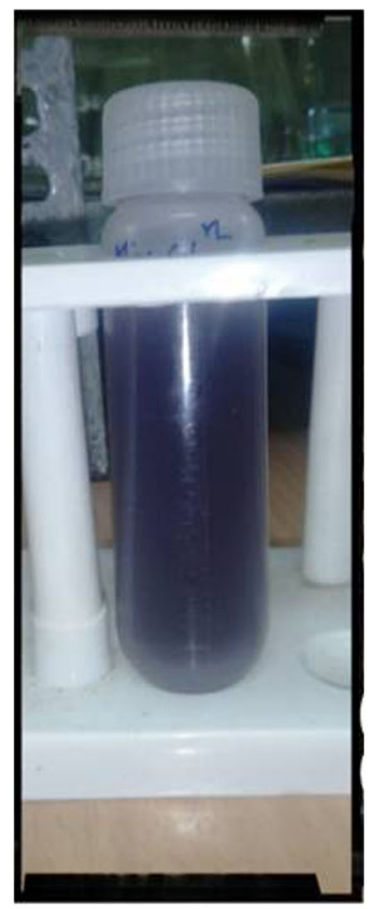

c Nanoparticle solution 
morphologically more or less spherical in nature with average particle sizes around $70 \mathrm{~nm}$ (Fig. 3). The presence of single morphological nanostructure in the HGNPs solution with non-existence of any other morphological

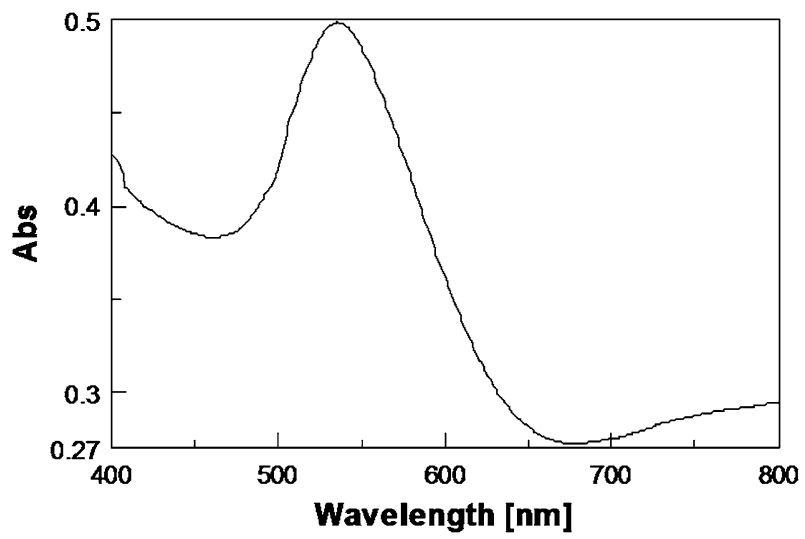

Fig. 2 UV-Vis spectra of HGNPs recorded between 400 and $800 \mathrm{~nm}$

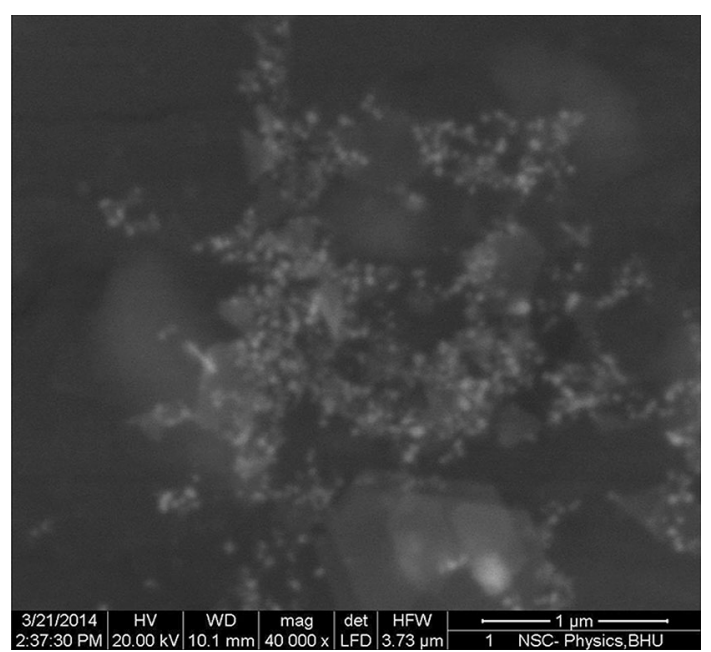

Fig. 3 Scanning electron microscopy (SEM) image showing the size of HGNPs nanostructures is also justified by the single SPR peak obtained by UV-Vis spectrophotometer (Fig. 2) as discussed in the earlier sections. Micrograph shows the highly dense and evenly arranged spherical HGNPs of approximately 50-80 nm in size with both SEM (Fig. 3) and high resolution transmission electron microscope (HRTEM) (Fig. 4). Moreover, HRTEM or TEM provides better image in comparison to SEM. However, to be more specified and for a clear image, SAED pattern of HGNPs was also performed by HRTEM. Recorded SAED pattern proves crystalline nature of synthesized HGNPs with hexagonal texture (Fig. 4). Most probable molecular reason for the formation of herbal gold crystal of HGNPs observed both in SEM and TEM, that the organic matrix must be comprised of gold binding proteins with amino acid moieties. Presence of gold binding amino acid moieties in the protein extracted from leaf could be serving as nucleation point which is in accordance to the finding of other scientific group on the silver nanoparticles. This might be the reason for the crystal structure of HGNPs we observed in Fig. 3.

\section{Zeta potential of HGNPs at different $\mathrm{pH}$}

Clear disposable zeta cell was used to calculate the zeta potential of samples at different $\mathrm{pH}$ that is at $\mathrm{pH} 6, \mathrm{pH} 7$ and $\mathrm{pH} 10$ at fixed temperature $25^{\circ} \mathrm{C}$. At $\mathrm{pH} 6$ zeta potential is $-9.62 \mathrm{mV}$ that represents poor quality, means unstable HGNPs without generation of distribution graph. At $\mathrm{pH} 7$ zeta potential value is $-25.7 \mathrm{mV}$, with zeta deviation $6.68 \mathrm{mV}$ and conductivity $0.588 \mathrm{mS} / \mathrm{cm}$ represents good quality but unstable nanoparticles (Fig. 5). However, at pH 10 zeta potential value is $-35.9 \mathrm{mV}$, with zeta deviation $7.41 \mathrm{mV}$ and conductivity $3.19 \mathrm{mS} / \mathrm{cm}$ which represents good quality and comparatively better stability of HGNPs (Fig. 6) than what we observed at $\mathrm{pH} 6$ and at $\mathrm{pH}$ 7. Zeta potential values may be positive or negative but values above than $-30 \mathrm{mV}$ or $+30 \mathrm{mV}$ favour the good quality
Fig. 4 Transmission electron microscopy (TEM) and selected area electron diffraction $(S A E D)$ image showing the size, morphology and texture of HGNPs

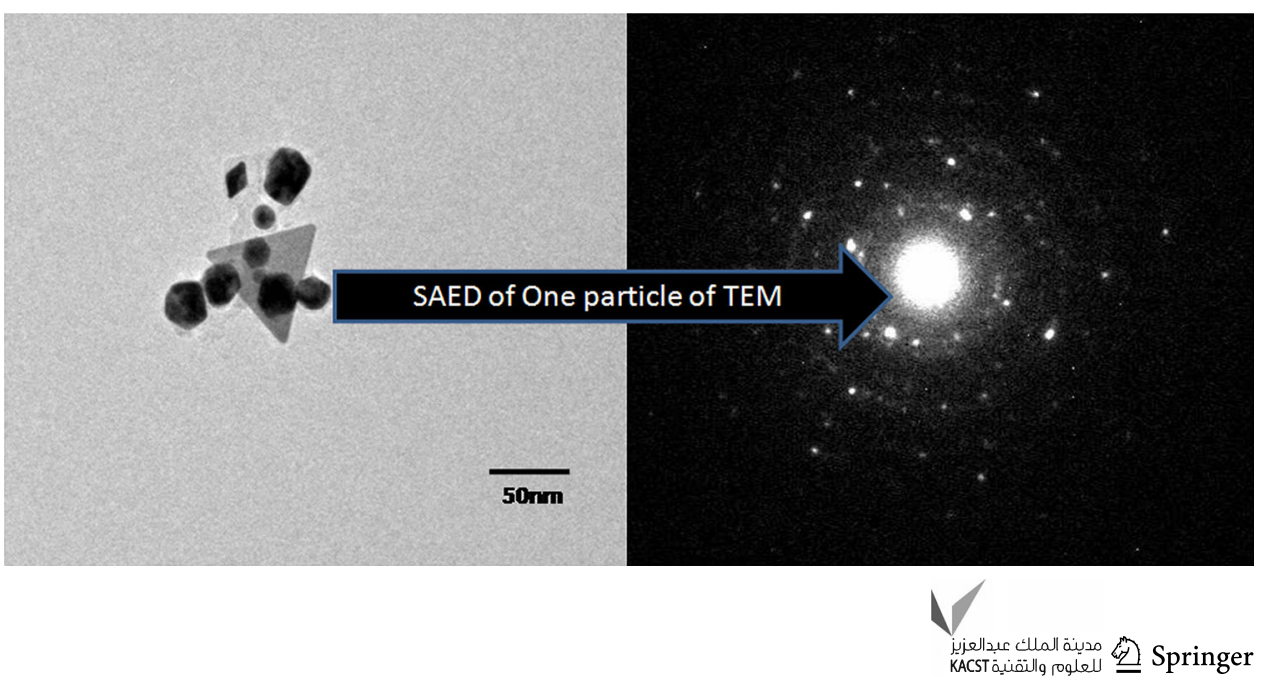


Fig. 5 Zeta potential value and zeta potential distribution graph of HGNPs at $\mathrm{pH} 7$
Fig. 6 Zeta potential value and zeta potential distribution graph of HGNPs at $\mathrm{pH} 10$

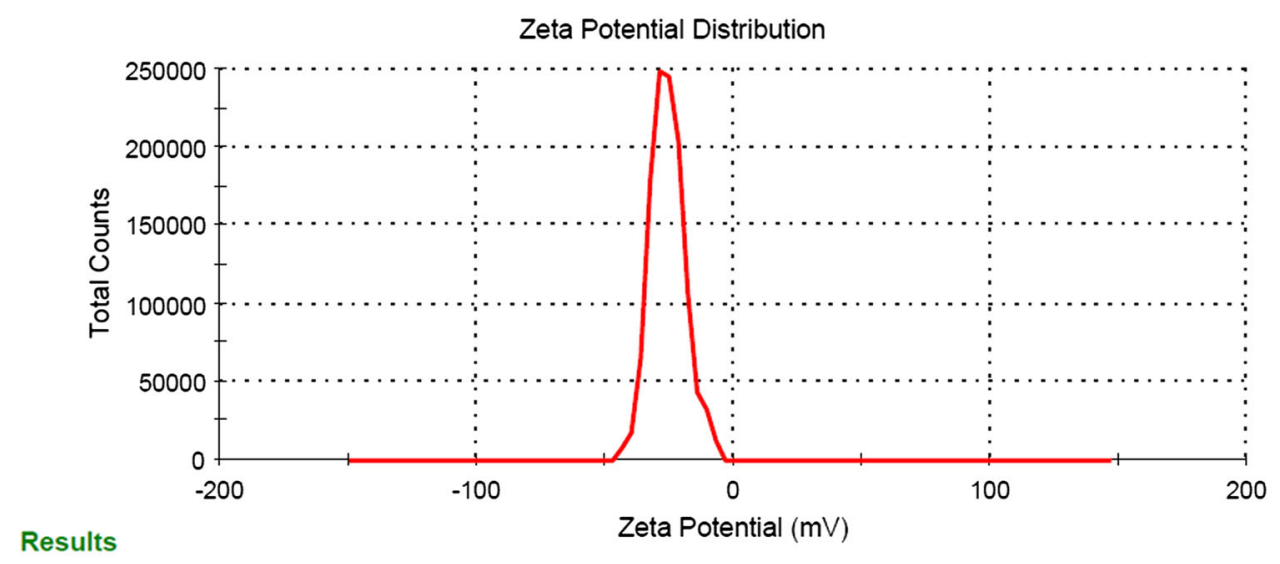

Zeta Potential (mV): -25.7

Zeta Deviation (mV): 6.68

Conductivity $(\mathrm{ms} / \mathrm{cm}): 0.588$

Result quality: Good

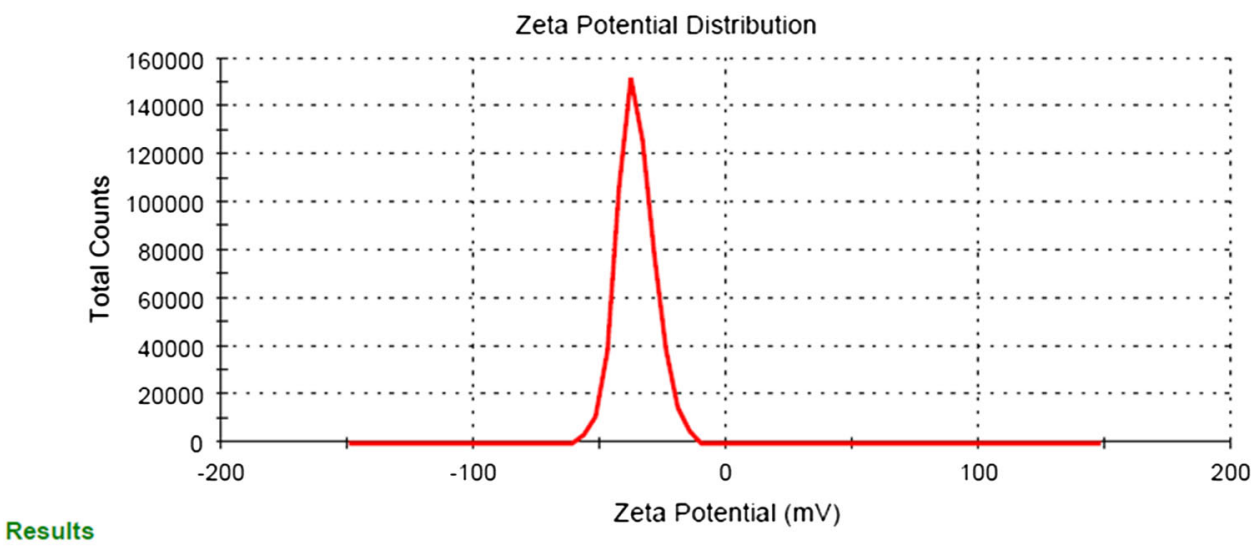

Zeta Potential (mV): -35.9

Zeta Deviation $(\mathrm{mV}): 7.41$

Conductivity (ms/cm): 3.19

Result quality : Good and stability of nanoparticles and such nanoparticles can be stored for the longer period of time. HGNPs that have zeta potential of $-35.9 \mathrm{mV}$ could be stored up to 2 months without compromising its quality and stability.

Effect of temperature, salt concentration and $\mathrm{pH}$ on the stability of HGNPs

Absorbance spectra of HGNPs were recorded at different temperature that is at $55,65,75$ and $85^{\circ} \mathrm{C}$; different concentration of $\mathrm{NaCl}$ that is at 1,2,3,4 and 5; with different $\mathrm{pH}$ that is at $\mathrm{pH} 6,7,9$ and 10. At these various conditions we observed peak at wavelength $540 \mathrm{~nm}$. This shows that synthesized HGNPs is stable at different temperature, salt concentrations and $\mathrm{pH}$. However, with an increase in temperature (Fig. 7) and salt concentration (Fig. 8) separately, there was a decrease in the absorbance while after increasing $\mathrm{pH}$ there was increase in the absorbance values of nanoparticles (Fig. 9) at $540 \mathrm{~nm}$. Overall, it was observed that synthesized HGNPs showed substantial stability up to 2 months at various conditions including lower $55^{\circ} \mathrm{C}$ to higher temperature $85^{\circ} \mathrm{C}$, lower salt concentration $1 \mathrm{M}$ to higher $5 \mathrm{M}$ and at lower $\mathrm{pH} 6$ to higher $\mathrm{pH} 10$, as revealed by homologous peaks at $540 \mathrm{~nm}$. This could be co-related with the storage of HGNPs for longer time period. The zeta potential value was $-35.9 \mathrm{mV}$ for synthesized HGNPs at $\mathrm{pH} 10$ showing its good quality with better stability in comparison to $\mathrm{pH} 6$ and $\mathrm{pH}$ 7. Based on our observation we recommend that for storage of HGNPs and other herbal prepared nanoparticles, $\mathrm{pH} 10$ could be more appropriate in comparison to any other $\mathrm{pH}$ value and before medicinal use, the $\mathrm{pH}$ could be finally adjusted to the normal physiological $\mathrm{pH}$. 
Fig. 7 UV-Vis spectra of HGNPs recorded between 400 and $800 \mathrm{~nm}$ at different temperature: a $55^{\circ} \mathrm{C}, \mathbf{b} 65^{\circ} \mathrm{C}$, c $75{ }^{\circ} \mathrm{C}, \mathbf{d} 85{ }^{\circ} \mathrm{C}$
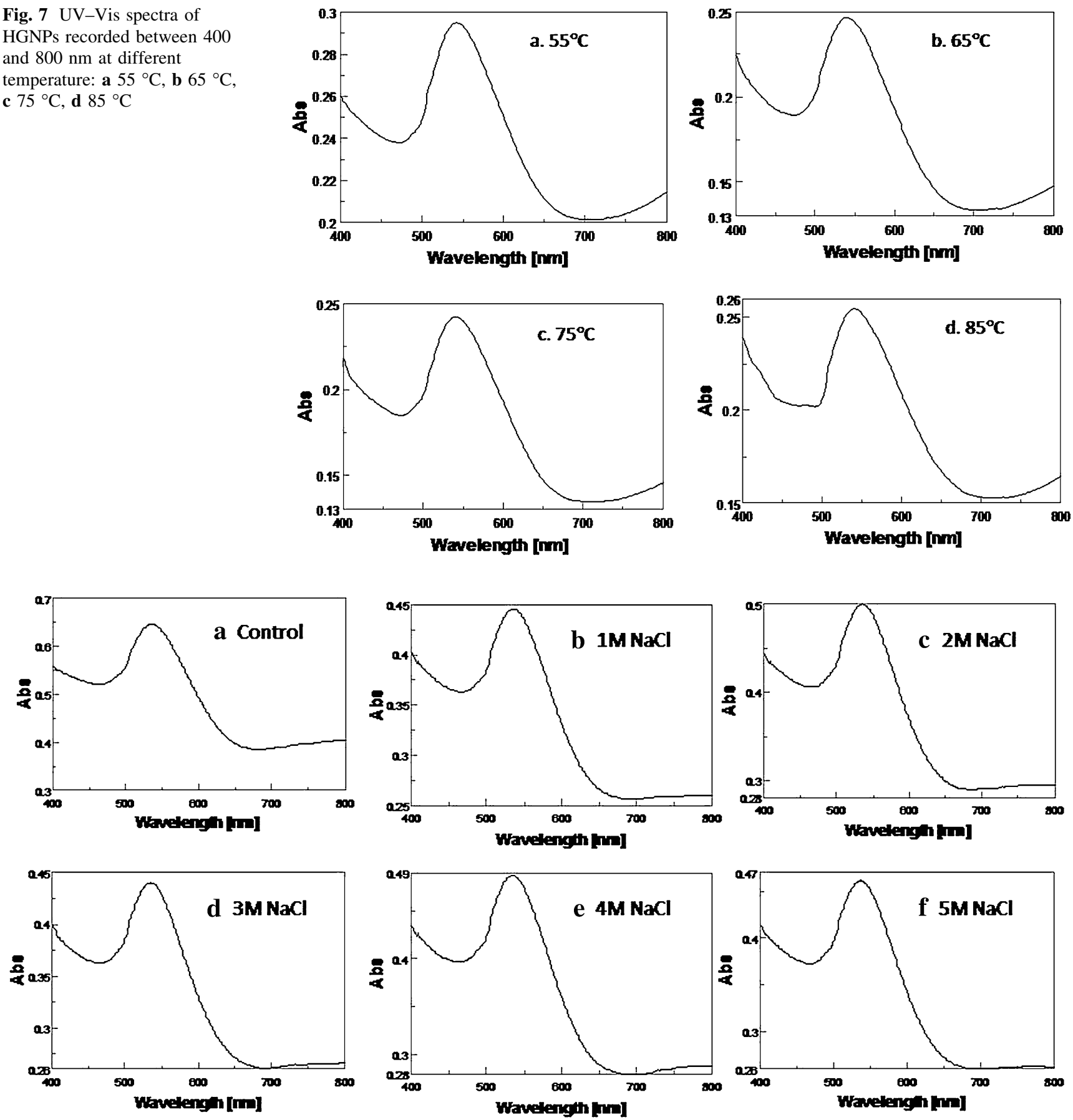

Fig. $8 \mathrm{UV}-$ Vis spectra of synthesized HGNPs recorded between 400 and $800 \mathrm{~nm}$ at different concentration of $\mathrm{NaCl}$ a control (DDW), b $1 \mathrm{M}$, c $2 \mathrm{M}$, d $3 \mathrm{M}$, e $4 \mathrm{M}$, f $5 \mathrm{M}$

Cytotoxicity assay

HGNPs with 20, 80 and $100 \mu \mathrm{g} / \mathrm{ml}$ concentration show 96, 95 and $94 \%$ spleenocyte cells viability, respectively, after $1 \mathrm{~h}$ of incubation of pre-treated cells (Fig. 10). This shows that, up to $100 \mu \mathrm{g} / \mathrm{ml}$ the freshly synthesized HGNPs are non-cytotoxic to spleenocyte cells and could be permissible dose for therapy. The concentration of $200 \mu \mathrm{g} / \mathrm{ml}$ HGNPs is slightly toxic but insignificant showing $17 \%$ of spleenocyte cells death, while $400 \mu \mathrm{g} / \mathrm{ml}$ concentration might be considered as a sub-lethal dose showing $67 \%$ of spleenocyte cells viability (i.e., $33 \%$ growth inhibition) upon $1 \mathrm{~h}$ of incubation in comparison to control (without HGNPs treatment) in $\mathrm{CO}_{2}$ incubator (Fig. 10). 
Fig. 9 UV-Vis spectra of synthesized HGNPs recorded between 400 and $800 \mathrm{~nm}$ at different $\mathrm{pH}$ a $\mathrm{pH} 6, \mathbf{b} \mathrm{pH} 7$, c $\mathrm{pH} 9, \mathbf{d} \mathrm{pH} 10$
Fig. 10 Cell viability in percentage $(\%)$ with different concentration of HGNPs (20, $80,100,200$ and $400 \mu \mathrm{g} / \mathrm{ml}$ ). $C$ control (without any treatment represents $100 \%$ viability). Data reported as mean \pm SEM of triplicate experiments performed in similar condition using a Student's $t$ test. $P<0.05$ were considered statistically significant
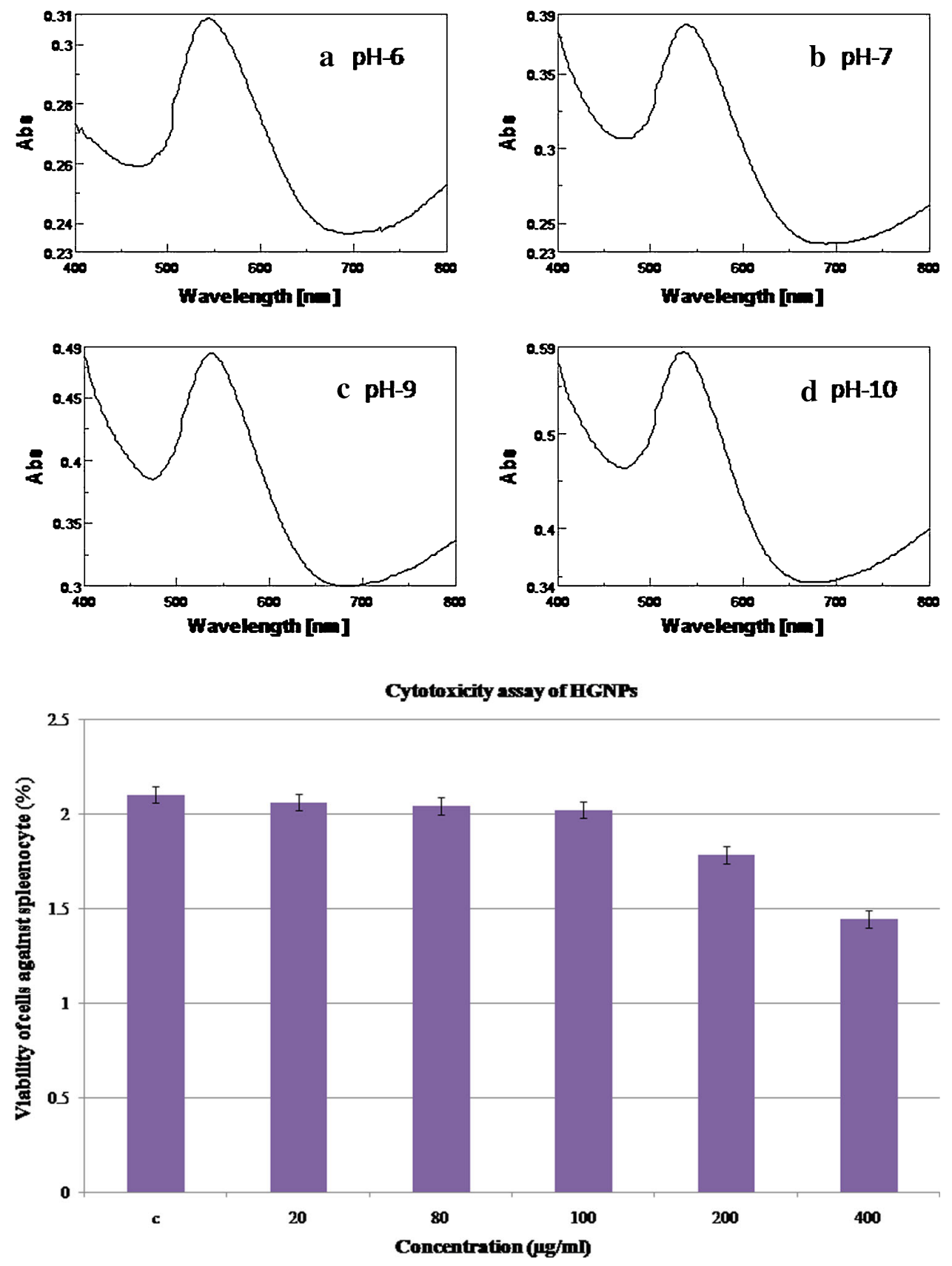

\section{Conclusions}

Here, green nano-biotechnological approach for the biogenic synthesis of HGNPs is applied using the leaf extract of medicinal plant A. aspera. Change in colour of leaf extract from initial dark brown to dark colloidal purple within 30 min after addition of gold chloride solution show the first sign for synthesis of HGNPs, which is further characterized by the UV-Vis spectrophotometer. SPR absorption peak at $540 \mathrm{~nm}$ confirm the presence of monodispersed gold nanoparticles in the solution. The size, shape and morphology of freshly synthesized HGNPs were characterized and identified by using SEM, TEM and TEM-SAED techniques. Micrograph obtained by SEM and TEM indicates that synthesized HGNPs were morphologically spherical and lay in the range of $50-80 \mathrm{~nm}$ with average range of size $70 \mathrm{~nm}$. TEM-SAED favours hexagonal texture in crystallized HGNPs. Presence of peak at $540 \mathrm{~nm}$ with different conditions of temperature, salt concentration and $\mathrm{pH}$ illustrate that, synthesized HGNPs are stable in all conditions but comparatively more stable up to 2 months at $\mathrm{pH} 10 / 25^{\circ} \mathrm{C}$ confirmed by zeta potential. We observed $-35.9 \mathrm{mV}$ of zeta potential which is an evidence of good quality and better stability of synthesized 
HGNPs, as zeta potential values above $\pm 30 \mathrm{mV}$ is considered for stable nature and good quality for any other nanoparticles. Cytotoxicity assay was performed on spleenocytes in vitro to check the toxicity level of HGNPs. Synthesized HGNPs are non-cytotoxic up to $100 \mu \mathrm{g} / \mathrm{ml}$ on spleenocyte cells, which is an indication that synthesized HGNPs may be used as nano-medicine.

Hence, we can propel that this biogenic synthesis method is very simple, cost effective, rapid and completely natural for the synthesis of HGNPs. To the best of our knowledge current protocol deals the shortest time period for the synthesis of HGNPs using herbal plant extract with good quality and stability in $\mathrm{pH}$ dependent manner with non-toxic up to $100 \mu \mathrm{g} / \mathrm{ml}$. The protocol could be alternative for the conventional Turkevich method (Turkevich et al. 1951). These synthesized HGNPs can be used in drug delivery and molecular diagnosis processes more competently and with different valuable biomedical and pharmaceutical applications.

Acknowledgments Alok Tripathi is thankful to University Grant Commission (UGC), New Delhi for awarding Junior Research Fellowship (JRF) for providing financial support. The corresponding author is thankful to DST-PURSE \& DBT for the research grant support to the School of Biotechnology. Special thanks to NSCDepartment of physics, BHU for SEM/TEM. We thank the Lab attendant Mr. Sunil Kumar Yadav for taking care of lab works.

Open Access This article is distributed under the terms of the Creative Commons Attribution License which permits any use, distribution, and reproduction in any medium, provided the original author(s) and the source are credited.

\section{References}

Ankamwar B, Chaudhary M, Sastry M (2005) Gold nanotriangles biologically synthesized using tamarind leaf extract and potential application in vapor sensing. Synth React Inorg Metal Org Nano Metal Chem 35:19-26

Bhattacharya R, Murkherjee P (2008) Biological properties of naked metal nanoparticles. Adv Drug Deliv Rev 60:1289-1306

Bhumkar DR, Joshi HM, Sastry M, Pokharkar VB (2007) Chitosan reduced gold nanoparticles as novel carriers for transmucosal delivery of insulin. Pharm Res 24:1415-1426

Chandran SP, Chaudhary M, Pasricha R, Ahmad A, Sastry M (2006) Synthesis of gold nanotriangles and silver nanoparticles using Aloevera plant extract. Biotechnol Pro 22:577-583

Chandrasekharan N, Kamat PV, Hu J, Jones G (2000) Dye capped gold nanoclusters: photoinduced changes in gold/rhodamine $6 \mathrm{G}$ nanoassemblies. J Phys Chem 104:11103-11109

Gardea-Torresdey JL, Parsons JG, Gomez E, Peralta-Videa J, Troiani HE, Santiago P et al (2002) Formation and growth of Au nanoparticles inside live alfalfa plants. Nano Lett 2:397-401

Gardea-Torresdey JL, Gomez E, Peralta-Videa J, Parsons JG, Troiani HE, Santiago P et al (2003) Alfalfa sprouts: a natural source for the synthesis of silver nanoparticles. Langmuir 19:1357-1361

Gericke M, Pinches A (2006) Biological synthesis of metal nanoparticles. Hydrometallurgy 83:132
Gilaki M (2010) Biosynthesis of silver nanoparticles using plant extracts. J Biol Sci 10:465-467

Henglein A (1993) Physicochemical properties of small metal particles in solution: microelectrode reactions, chemisorption, composite metal particles, and the atom-to-metal transition. J Phys Chem 97:215457-215471

Huang J, Chen C, He N, Hong J, Lu Y, Qingbiao L et al (2007) Biosynthesis of silver and gold nanoparticles by novel sundried Cinnamomum camphora leaf. Nanotechnology 18:105-106

Królikowska A, Kudelski A, Michota A, Bukowska J (2003) SERS studies on the structure of thioglycolic acid monolayers on silver and gold. Surf Sci 532:227-232

Kumar A, Mandal S, Selvakannan PR, Pasricha R, Mandale AB, Sastry M (2003) Investigation into the Interaction between surface-bound alkylamines and gold nanoparticles. Langmuir 19:6277-6282

Mohanpuria P, Rana NK, Yadav SK (2008) Biosynthesis of nanoparticles: technological concepts and future applications. J Nanopart Res 10:507-517

Narayan C, Kumar A (2013) Identification and characterization of phenolic compounds in hydro methanolic extract of Achyranthes aspera (HMEA) by UPLC and MALDI-TOF-MS and in vivo antioxidant activity. Orient Pharm Exp Med 13:51-59

Narayan C, Kumar A (2014) Antineoplastic and immunomodulatory effect of polyphenolic components of Achyranthes aspera (PCA) extract on urethane induced lung cancer in vivo. Mol Biol Rep 41:179-191

Narayanan KB, Sakthivel N (2008) Coriander leaf mediated biosynthesis of gold nanoparticles. Mater Lett 62:4588-4590

Peto G, Molnar GL, Paszti Z, Geszti O, Beck A, Guczi L (2002) Electronic structure of gold nanoparticles deposited on $\mathrm{SiOx} /$ Si(100). Mater Sci Eng C19:95-99

Prabhu N, Divya TR, Yamuna G (2010) Synthesis of silver phyto nanoparticles and their antibacterial efficacy. Digest J Nanomater Biostruct 5:185-189

Shankar SS, Rai A, Ahmad A, Sastry M (2004a) Rapid synthesis of $\mathrm{Au}, \mathrm{Ag}$, and bimetallic Au core Ag shell nanoparticles using neem (Azadirachta indica) leaf broth. J Colloid Interface Sci 275:496-502

Shankar SS, Rai A, Ankamwar B, Singh A, Ahmad A, Sastry M (2004b) Biological synthesis of triangular gold nanoprisms. Nat Mater 3:482-488

Sharma VK, Yngard RA, Lin Y (2009) Silver nanoparticles: green synthesis and their antimicrobial activities. Adv Coll Int Sci 145:83-96

Singh V (1995) Traditional remedies to treat asthma in North West and trans himalayan regions in $\mathrm{J}$. and $\mathrm{K}$. state. Fitoterapia 66:507-509

Singh M, Kalaivani R, Manikandan S, Sangeetha N, Kumaraguru AK (2013) Facile green synthesis of variable metallic gold nanoparticle using Padina gymnospora, a brown marine macroalga. Appl Nanosci 3:145-151

Smitha SL, Philip D, Gopchandrana KG (2009) Green synthesis of gold nanoparticles using Cinnamomum zeylanicum leaf broth. Spectrochim Acta A Mol Biomol Spectrosc 74:735-739

Suresh A, Anandan T, Sivanandam G, Veluchamy G (1985) A pilot study of Naayyuruvi kuzhi Thailam in Eraippunoi (bronchial asthma). J Res Ayur Sidha 6:171-176

Tripathi SN, Chaturvedi GN, Dube GP (1963) Effect of Achyranthes aspera in the treatment of leprosy. J Med Sci 4:103-112

Turkevich J, Cooper-Stevenson P, Hillier J (1951) A study of the nucleation and growth processes in the synthesis of colloidal gold. Discuss Faraday Soc 11:55

Willems VDW (2005) Roadmap report on nanoparticles. W\&W Espana sl, Barcelona 